\title{
LA MINIATURA DEL ÁGUILA Y LA SERPIENTE EN LOS «BEATOS»
}

\author{
Carlos Cid \\ Isabel Vigil
}

\section{INTRODUCCIÓN}

La miniatura que estudiamos, la lucha entre un águila y una serpiente, está ligada a un texto concreto que, al adscribirla y narrar la historia, saca una consecuencia simbólica que se refiere a la Encarnación de Cristo. Este tema nada tiene que ver con el Comentario al Apocalipsis, pero forma parte de dos ramas de familias de estos manuscritos, justamente las más ricas, la II. a y la II.b, con excepción de $\mathrm{S}$ que es de la I'.

La explicación es sencilla. Con el tiempo, a la obra de Beatus se sumaron otros textos sagrados, consistentes en un resumen bíblico, especie de Evangeliario, y un Comentario al Libro de Daniel por San Jerónimo. Así, estos códices quedaron formados por un Evangeliario sintético (Evangelistas y genealogías), prólogos y Comentario de Beatus propiamente dicho, y el Comentario de San Jerónimo.

Esta tríplice organización de los manuscritos da lugar a las familias ya mencionadas, que son las que tienen o tuvieron esta miniatura, con la que se cierra la parte evangélica de las genealogías.

Como es lógico, la fuente de esta miniatura hay que buscarla necesariamente en una Biblia, $y$ así sucede en la de la Academia de la Historia y en la Biblia II de León.

La miniafura y el texto no tienen nada que ver con el Comentario del Apocalipsis, y por tanto puede asegurarse que no pudo figurar en el manuscrito originario, en el supuesto de que estuviera ilustrado. La familia I no la tiene porque se ciñe únicamente al Comentario de Beatus.

1 En nuestro trabajo seguimos la división en familias y por las siglas de los códices utilizadas por W. Neuss, por considerarlas las más difundidas. 


\section{ORIGENES}

El texto de la miniatura sale del mundo antiguo, una curiosa referencia científica a la manera de aquellos tiempos, y en determinado momento se cristianiza y adquiere una simbología. Creemos que esta transformación de la narración antigua en un contexto cristiano se realizó en la Iglesia hispánica en época mozárabe, y en los scriptoria de la región leonesa. Ni las Biblias catalanas ni las transpirenaicas utilizaron esta iconografía.

Que sepamos, esta miniatura o su texto sólo se encuentra en los manuscritos mozárabes o románicos de tradición mozárabe, y casi todos ellos apuntan hacia un scriptorium leonés. Si aceptamos que Magius la minió en el códice $\mathrm{M}^{2}$, y vemos que las genealogías de este manuscrito son idénticas a las de J y a las de la Biblia I de León ${ }^{3}$ y consideramos que el monasterio de San Miguel Arcángel, del que habla Emeterio en el códice tabarense en su panegírico de Magius, es San Miguel de Escalada, y si se tiene en cuenta que: las Biblias I y II de León y el Beato J pertenecieron a San Isidoro de León; el manuscrito $\mathrm{M}$ se hizo para un monasterio de los alrededores de León: la Biblia de la Academia de la Historia tiene en los textos semejanzas con las leonesas según Churruca ${ }^{4}$; todos los demás manuscritos que contienen esta miniatura son de la familia $\mathrm{II}^{b}$ derivados del códice de Tábara, comenzado por Magius; y que esta ilustración está al principio, ${ }^{5}$ llegamos a la conclusión de que la miniatura fue creada para una Biblia (no la I de León, que es algunos años posterior a Magius, sino para otra semejante a ella), y que pasó a los Beatos en el momento de su ampliación, y que fue el Comentario apocalíptico el que le dio mayor difusión.

Esta creación se debió a un miniaturista de la región leonesa de los siglos IX o X. Recordemos los nombres de Florencio, Facundo, Juan, Emeterio, Magius y otros tantos desconocidos, que poblaron las bibliotecas de estas tierras con su penoso trabajo, como evidencia Emeterio cuando se

${ }^{2}$ Hoy este manuscrito está privado de esta miniatura, pero en tiempos la tuvo, como demostraremos más adelante.

${ }^{3}$ Nos referimos a estas Biblias porque sus errores y aciertos nos llevan con mucha seguridad a emparentar los manuscritos. La Biblia I de Loón tampoco ticne esta ilustración, pero la poseyó, como lo demuestra su copia en la Biblia II. La Biblia I de León coincide también con la primera parte de los Beatos de la familia $\Pi^{\mathrm{a}}$ en la extrafla Anunciación con el Niño ya nacido, es decir, que todos los detalles nos llevan hacia León, que al fin y al cabo fue el Reino heredero del asturiano, de donde procedía el autor del texto de estos libros de tanto éxito keditorials, como diríamos hoy, que se mantuvieron incluso después del cambio litúrgico.

4M. Churruca, Influjo oriental en los temas iconográficos de la miniatura española, siglos $\mathrm{X}$ al $\mathrm{xII}$, Madrid, 1939. En la página 136 dice: ecomo la legionense, tiene numerosas notas marginales, tomadas de una antigua versión latinas.

${ }^{5}$ Magius murio durante la ejecución de este manuscrito, que fue continuado y acabado por Emeterius. 
conduele de los esfuerzos que tuvo que realizar para terminar su obra con estas célebres palabras: $O$ turre tabarense alta et lapidea insuper prima teca ubi Emeterius tribusque mensis - incuruior sedit et cum omni sua membra calamum conquassatus fuit.

Advirtamos además que en la liturgia mozárabe sólo había una fiesta dedicada a María, que era la de su advocación de maternidad divina. La Encarnación se celebraba el 18 de diciembre ${ }^{6}$, y era una de las festividades que tenían mayor número de misas en los manuscritos mozárabes. Únicamente la aventajaba la Epifanía?. Por lo tanto, es lógico que trataran de representar algo que para ellos tenía gran importancia.

\section{LOS TEXTOS}

El texto medieval que acompaña esta miniatura está escrito en un bajo latín gramaticalmente muy defectuoso en todos los aspectos, con errores ortográficos y de flexión, con variantes según los códices en estos detalles, e incluso palabras totalmente equivocadas - sin duda errores auditivosque de tomarse al pie de la letra dejarfan sin sentido lo que se narra. Buen ejemplo es gemmas referidas al águila, que evidentemente debe ser pennas (plumas), y así se rectifica en la traducción que incluimos más abajo. Este error aparece en los textos de S, G, H y Biblia II de León. El latín tan incorrecto está lejos de la corrección que todavía tenía empeño en mantener la época visigoda, da la clara impresión de ser posterior y de mano de persona que dominaba mal esta lengua antigua; sin embargo, no aparece ninguna forma de las llamadas de protorromance, que empiezan a prefigurar con bastante anticipación la formación de lo que más adelante serían las lenguas romances. No está en verso, pero a pesar de esto y de sus defectos, tiene un regusto poético y bello. La traducción es muy difícil, incluso es imposible matizar con toda seguridad ciertos pasajes, pero coherente en su conjunto. El texto latino, tomado literalmente del códice de Gerona, es el siguiente:

Quedam esse avis in regione orientis assetur que grandi et perduro armatoque rostro contra draconem quem audacius lacessit sibilis pugnatura cenum de industria expetit ecuius volutabro tetro habitu infecta sor-

${ }^{6}$ Esta festividad se celebraba ya desde muy antiguo. En el año $656 \mathrm{el}$ Concilio $\mathrm{X}$ de Toledo la establece para un día fijo, ya que hasta entonces había oscilado en diversos días según las regiones (canon I del citado Concilio).

${ }^{3}$ El Antifonerio de León le dedica siete misas, la sobrepuja la Epifanía con ocho, y la iguala la Natividad con otras siete. 
descit et diversorum gemmas colorum quibus eam indulgentia natura depinxit.

Et humili despecta vestita ita hostem nobitate deterreat et quasi vilitatis sue securitate decipiat. Caudam velut scutum ante faciem suam quedam ane bellatoris opponit audaci impetus in caput adversaril furentis adsurgit. Improviso orus sui telo stupentis bestie cerebrum fodit. Et sic mire calliditatis ingenio inmanem prosternit inimicum.

*Item dominus hac redentor noster contra serpentis antiqui humani generis suplantatorem ${ }^{8}$,

In forma hominis pugnatus ad militia salutis pupplice humana se infirmitata precinxit hac luto se nostras carnis involivitut impium deceptorem pia fraude deciperet et postremis priora celavit. Et velut caudam humanitatis ante faciem divinitatis obiecit et tamquam rostro fortissimo venenatam veteris homicide malitiam Bervo sui oris extinxit. Unde et apostolus dixit: Bervo oris sui inferficiet impium. Explicit ${ }^{9}$.

Desconocemos traducciones en lenguas modernas de este texto, excepto la alemana de Neuss, hecha sobre el códice $\mathrm{S}$, que no es perfecta ni completa ${ }^{10}$. Damos a continuación la castellana de $\mathrm{G}$ :

* Se cuenta que en la región del Oriente hay un pájamo con un pico grande, muy duro y como un arma; al luchar contra la serpiente, a la que hostiga audazmente con sus silbidos, busca intencionadamente barro revolcándose en él, impregnándose de un revestimiento oscuro mancha incluso las alas de diversos colores con los que la Naturaleza, en su esplendidez, lo pintó.

¿ $\mathrm{Y}$ degradado con una vestidura humillante aterroriza al enemigo por la novedad, y puede decirse que lo engaña con la seguridad de su propia bajeza. Opone su cola como un escudo ante su rostro con un cierto arte guerrero, y se alza con ímpetu audaz contra la cabeza del adversario enfurecido. Con un imprevisto dardo de su pico hiere el cerebro de la bestia. $\mathrm{Y}$ de este modo, con el ingenio de su maravillosa sagacidad abate al ingente adversario.

»De igual manera (se comporta) nuestro Señor y Redentor contra el suplantador de la antigua serpiente del género humano.

${ }^{8}$ Las palabras que entrecomillamos en este texto latino están en todos los manuscritos que poseen y conservan el texto. Serprende que falte en D, pero la explicación es muy sencilla: hay la anchura de un renglón que se deja en blaneo, también falta la letra inicial, una "Q", al comienzo de toda esta histona; si nos fijamos en $\mathrm{H}$, tamo la frase como la inicial se trazarom con otro color de tinta, la inicial por costumbre y el texto por ser clave para el simbolismo. En D se pensaba hacer así y se reservaron los espacios, que por la razón que sea no se completaron.

${ }^{9}$ Beato de Gerona, folio $19 \mathrm{y}$.

10 W. Neuss, Die Apokalypse des HI. Johannes in der altspanischen und altschrislischen Bibel-illustration, Münster in Westffalien, 1931. 
»Luchando en forma de hombre se ciño, para el combate de la salud del pueblo, con la debilidad humana, y envolvió nuestras carnes con el barro con el fin de engañar con un piadoso fraude al impío embaucador, y encubrió lo elevado con lo bajo. Y puso ante el rostro de la divinidad algo así como la cola de la humanidad, y como con un pico fortísimo extinguió la malicia envenenada del antiguo homicida con el Verbo de su boca. Por todo esto, también el apóstol dijo: Con el Verbo de su boca mataré al impío. Terminas".

Este texto es una versión libremente adaptada procedente de un pasaje de la Historia Natural del autor clásico Plinio el Viejo. En el escrito latino los protagonistas de esta lucha son el ciervo y el águila, mientras que en nuestro texto el cuadrúpedo es sustituido por la serpiente. No tuvo que ir muy lejos el autor que cristianizó la historia para hacer este cambio, ya que la enemistad del águila y la serpiente era un tema muy generalizado en la literatura latina ${ }^{12}$, y porque el propio Plinio se refiere a ella a continuación, ya que «draco» en su época nunca significaba «dragón», sino «serpiente». Además, esta sustitución del ciervo por el reptil tiene una fácil explicación. En el Bestiario el ciervo es un animal de signo positivo (en los textos evangélicos simbolizan las almas de los justos, etc.), y por esto era preciso el cambio por un animal de simbolismo negativo, como la serpiente (demonio, el mal en sentido genérico), para dar sentido lógico a lo que se iba a explicar exegéticamente en el texto mozárabe. El autor de estas transformaciones alteró las palabras de Plinio a su gusto y con muy poco escrúpulo, cosa frecuente en su época.

El antiguo texto de Plinio dice literalmente:

Primo et secundo generi non minorum tantum quadripedum rapina, sed etiam cum ceruis proelia. Multum puluerem uolutatu collectum insidens cornibus excuit in oculos, pinnis uerberans, donec pracipitet in supes. Nec umus hostis illi satis: est acrior cum dracone pugna multoque magis anceps, etiamsi in aere. Qua hic consectatur aquilae auditate malefica; at illa ob hoc rapit ubicumque uisum, ille multiplici nexu ligat, ita se inplicans ut simul decidat ${ }^{13}$.

${ }^{11}$ Agradecemos esta traducción y los consejos filológicos a los Drs. D. José Moralejo Alvarez, D. Francisco Pejenaute Rubio y D. Cristóbal Rodríguez Alonso, catedrático y profesores adjuntos respectivamente del Departamento de Filología Clísica de la Facultad de Filosoffa y Letras de la Universidad de Oviedo.

12 ArIstóteles, $\boldsymbol{H}$. A., IX, 1, 609, dice: «El águila y el dragón son enemigos porque el águila se nutre de serpientes. Homero, Iliada, XII, 201. Cicerón, De diu, I, 47, 106. Horacio, Oda IV, 4, 11. Virgilio, Eneida, XI, 751, 6. Ovmio, etc.

${ }^{13}$ PLinfo El viejo, Historia Natural, libro X, (IV, 5). Tomamos el texto de la edición đe E. DESAINT-DENIS, en Collection des Universités de France, París, 1961. 
«El águila de la primera o de la segunda especie no se contenta con arrebatar los pequeños cuadrúpedos, sino que lucha con los ciervos. Revolcándose por el suelo se cubre con abundante polvo, luego se precipita sobre los cuernos del ciervo y le sacude el polvo en los ojos, golpeándole con sus alas hasta que lo precipita por las rocas. $\mathrm{Y}$ no le basta un solo enemigo: mantiene con el dragón (serpiente) una lucha más cruenta y mucho más incierta, aunque en los aires. Éste busca los huevos del águila con una avidez destructora; por su parte, el águila lo eleva en cualquier lugar en que lo vea: pero el otro encierra sus alas con múltiples nudos, trabándose de tal modo que caen juntos ${ }^{14}, \infty$

La comparación de la Divinidad con las aves es una idea innata y casi universal en todas las religiones. En la cristiana el catálogo sería largo, basta recordar la paloma, el pelícano o el kaladrius, como muestra. Concretamente, el zoomorfismo de Cristo bajo la apariencia de águila fue siempre una iconografía muy generalizada en la literatura cristiana, y así la encontramos en la Patristica, como en Pedro de Capua y Rábano Mauro ${ }^{15}$. Que así sucedió a propósito de la historia de Plinio, lo prueba J.B. Pitra ${ }^{16}$, que en su conocida recopilación de anécdotas tomadas de los Santos Padres cita casi literalmente un fragmento del texto antes incluido:

Aquila, ut dicit Plinius, pugnat cum cervo, et super cornua ejus sedens, pulverum collectum excutit oculos ejus, pennis ora verberans, donec in rupes eum praecipitet ${ }^{17}$.

Lo que traducido dice:

«El águila, según dice Plinio, lucha con el ciervo, y posándose sobre sus cuernos, le arroja a los ojos el polyo que ba recogido, golpeándole la boca con las plumas, de forma que lo precipita en las rocas.»

No olvidemos que el águila era en el mundo clásico el emblema de Júpiter, padre de los dioses, y es lugar común que el cristianismo se nutrió de las fuentes paganas para crear su propia iconografía. Con esta transposi-

14 Traducimos este texto en castellano de la versión francesa que acompaña al latino, en la edición citada en ia nota anterior.

$15 \mathrm{El}$ propio Beatus hace numerosas alusiones al águila de carácter místico y la identifica con Cristo, en otras partes del texto que son independientes de la miniatura que comentamos.

16 M. Churruca, op. cit.

17 J.B. PrrRA, Spicilegium Solesmense complectens Sanctorum Patrum, Scriptorumque Ecclesiasticorum anecdota Hactemis Opera selecta a Graecis Orientalibusque et latines codicibus, París 1855, De Aquila, tomo III, p. 71. 
ción la simbología que se quiso dar al texto quedó perfecta: Cristo venció con su Encarnación al dragón infernal.

Ignoramos el momento y el autor que por primera vez cristianizó el texto. Lo hizo sin duda alguien familiarizado con la Historia Natural de Plinio y al mismo tiempo con la cultura de la Baja romanidad, ya que hay un detalle que apunta hacia esta época. Se trata de la disposición caligráfica del texto y de su enmarque, que forman una cruz. Esto nos llevaría a Porfirio en su Carmina Figurata, y a su émulo de época carolingia Rábano Mauro con sus De laudibus sanctae Crucis.

Los griegos y los latinos se entretuvieron con estas poesías escritas en disposición figurada. Así sucede, por ejemplo, en el manuscrito 647 del Museo Británico de Londres (Harley), en cuyo folio 12 se ve un centauro que está formado por el texto de un comentario, y únicamente la cabeza y las extremidades están pintadas por los procedimientos figurativos normales; el códice conservado es carolingio del siglo IX, pero es copia de un perdido original griego del siglo VI. Se trata de un procedimiento que se remonta a los caligramas griegos.

En la literatura latina encontramos al citado Porfirio, poeta del siglo IV, que utilizó también este artificio en su obra. En cuanto a Rábano Mauro, siguió esta moda en su opúsculo De laudibus sanctae Crucis, dedicado a San Martín de Tours en el año 845. Estos alardes fueron muy frecuentes en la escritura de los códices mozárabes, y no olvidemos que en muchos existen acrósticos donde se enmascara el nombre de los autores, la fecha y lugar donde se hicieron, con preciosismo e ingenio caligráficos de semejante e idéntica procedencia. Incluso en los textos marginales que contienen correcciones o añadiduras de fragmentos olvidados por el copista en el cuerpo del escrito, se advierte la tendencia a darles formas caprichosas y enmarcadas por un fino trazo, que si no llegan a lo figurativo, al menos tienen cierto valor ornamental, sobre todo en los códices más antiguos, que revelan una fuerte inclinación innata subsistente entre los mozárabes a este procedimiento de sintetizar figura y texto en una misma imagen.

\section{LAS MINIATURAS DEL ÁGUILA Y LA SERPIENTE EN LOS DISTINTOS MANUSCRITOS}

Analizados los textos, recordemos que forman parte inseparable con la miniatura que plásticamente los ilustra. Pero al estudiarlos hallamos varios problemas: hay manuscritos que tienen texto y miniatura, otros que sólo poseen el texto, y los que únicamente presentan la miniatura. Tienen ambos elementos G (fol. 18 v. y 19 v.), S (fol, 12 v. y 13 r.) entre los Beatos; además, la Biblia II de León, y las Moralia de San Gregorio (fol. 172 v.). En el Beato Tu no hay más que el texto (fol. $16 \mathrm{r}$.) por pérdida material de 
la miniatura ${ }^{18}$; en el caso de $\mathrm{H}$ la miniatura no desaparecio, sino que se fundió con otra y originó curiosamente una nueva. En U (fol. V v.) solamente se trazó el dibujo, pero no se rellenó de color, por lo que por alguna causa quedó inacabada, y se dejó el espacio destinado al texto, pero no llegó a escribirse. En cuanto a la Biblia de la Real Academia de la Historia, reprodujo el águila y la serpiente de manera espectacular, a doble folio, pero tampoco consignó el texto, pese a que en el folio anterior quedó pergamino en blanco.

Por otra parte, hay códices que carecen hoy de la miniatura y del texto, pero que primitivamente los tuvieron. Hay que advertir que se destinaron a los primeros folios, que junto con los últimos son siempre los más expuestos a toda clase de deterioros y pérdidas durante el transcurso de los siglos y de sus acontecimientos.

No hay duda de que esta ilustración la poseyó la Biblia I de León, del año 960, porque aparece en su copia directa la Biblia II, de 1162. Tampoco está hoy en $\mathrm{M}$, de la familia $\mathrm{II}^{\mathrm{a}}$, pero es indudable que la tuvo porque de este manuscrito pasó, como ya dijimos, a la familia $\mathrm{II}^{b}$. Lo corrobora que no sólo falta esta miniatura, sino también el folio anterior con la ascendencia de María y de José, o sea la última genealogia, y justamente el águila y la serpiente cierran esta parte del libro. En el códice queda en la actualidad encarada la penúltima genealogía y el texto del Comentario de Beatus, circunstancia lógicamente imposible. D y V nunca tuvieron la miniatura, a pesar de que estilísticamente pertenecen a esta familia, pero es por carecer de esta primera parte evangélica. J presenta la encuadernación alterada y no tiene la miniatura, y por lo tanto es imposible afirmar ahora si la tuvo o no.

En cuanto a la familia $\mathrm{II}^{\mathrm{b}}$, el códice $\mathrm{T}$, que casi se puede asegurar que fue la cabeza del grupo por la intervención de Magius, es un ejemplar bárbaramente despojado de la mayoría de las miniaturas, bien por el robo del folio completo, o lo más frecuente, por el recorte de las ilustraciones con tijeras. Hoy sólo le quedan siete ${ }^{19}$. Es seguro que tuvo la ilustración del águila y la serpiente, ya que sus descendientes $\mathrm{G}$ y Tu por un lado, y por otro $\mathrm{R}$ y $\mathrm{H}$, conservan sus huellas.

En todos los manuscritos esta miniatura aparece sin enmarque y pintada directamente sobre el pergamino, $\sin$ fondo ni zonas coloreadas, lo que es norma general en las ilustraciones que no deben considerarse extravagantes en los Beatos más ricos, es decir, las que pertenecen al texto del Comentario al Apocalipsis de Beatus, ya que lo mismo ocurre con las del Comentario al Libro de Daniel por San Jerónimo, añadido al final.

18 Véase C. CiD e I. ViGil, El Beato de la Biblioteca Nacional de Turin, ya citado, p. 205 y s.

19 Esencialmente el texto sólo falta cuando formaba parte material de los fragmentos correspondientes a las miniaturas cortadas, y no fue robado por sí mismo, sino arrastrado por ellas. 
Los orígenes plásticos de la miniatura son hoy totalmente desconocidos. Es evidente la existencia de un texto de Plinio que puede seleccionarse claramente entre todos los pasajes literarios de la Antigüedad como base de la historia. Como vimos, su cristianización simbólica no presenta un hito tan seguro, pero se puede rastrear con alguna aproximación, y al menos conocemos el modelo y la intención. No ocurre lo mismo con la imagen. Aves que luchan con serpientes son tan numerosas en todos los tiempos y lugares, que se encuentran desde el Extremo Oriente hasta la América precolombina, sin que tengan nada que ver entre sí. Todo el Próximo Oriente fue pródigo en este tipo de representaciones, desde Mesopotamia y el Asia Anterior hasta el antiguo Egipto. En éste era frecuente el dios Ibis en forma de pájaro devorando una culebra. El número de representaciones en toda clase de obras de arte formaría un catálogo ingente y siempre incompleto. No es extraño que desde los autores romanos hasta los escritores cristianos se burlaran de pueblos cultos capaces de adorar a dioses animalísticos ahitos de repulsivas culebras.

El arte clásico recogió el tema, pero poco sabemos de su pintura y menos de sus miniaturas. Se trata por lo tanto de una idea universal que ofrecía modelos a cualquiera que los necesitara. En ocasiones el parentesco con Plinio es directo e indudable, como en el bello mosaico del palacio de los emperadores cristianos de Constantinopla, de fines del siglo v o comienzos del $\mathrm{vv}^{20}$. Y no cabe duda de que en algún momento alguien se inspiró en este tipo de escena y la unió al texto cristianizado de este autor.

El resultado fue una miniatura bellísima, de variados y vivos colores, a los que por naturaleza se prestaban ambos animales. El polvo de la nube es para los miniaturistas mozárabes un pretexto más para exhibir su gusto decorativo y caligráfico completamente antinatural. Entre sus sucesores románticos hay unos que siguen muy de cerca el modelo, y por lo tanto tienen idénticas características que los mozárabes, aunque ya peor comprendidas (S y Biblia II), otros están ya claramente por las nuevas modalidades del arte románico (H y R).

\section{Beato $G$}

La miniatura ocupa un folio entero, el $18 \mathrm{v}$. El águila es un gran pájaro bien dibujado y de bellos colores, quizás demasiado estático y que no

20 El mosaico, de inmensa belleza y naturalismo, puede verse reproducido en A. GraBAR «La edad de oro de Justinianow, en El Universo de las formas, Madrid 1960, fig. 106. El estar en su suelo demuestra que en este caso se pensaba más en Historia Natural, próxima a Plinio, que en una simbología religiosa. Un cristiano jamás habría puesto en el suelo un personaje o símbolo sagrado, ni menos atreverse a pisar a Cristo. 
justifica su posición espacial, ya que las alas plegadas excluyen su elevación en el aire, y las garras no se apoyan en ninguna parte, ya que quedan distanciadas por encima de la cola de la serpiente, pero sin asirla, como sería lo natural. La nube de polvo es una gran masa interpretada como una superficie con detalles decorativos, como sucede en todos los códices en que se representa, pero con un detalle naturalista que falta en los demás. Esa masa, demasiado pesada y ornamentada para que pueda identificarse con el polvo físico, si no conociéramos el texto, está rodeada de una banda de puntitos que evidentemente representan el polvo de manera mucho más realista. Clava el pico en la cabeza de la serpiente, que ondula su cuerpo y por dos veces forma lazos, pero sin tocar al ave, excepto en el lugar en donde ésta la ataca.

Hay un detalle muy curioso que aparece como novedad única en esta miniatura, y es un gracioso y estilizado arbolillo con frutos, en el lado izquierdo, con dos ramas simétricas bajas con otros tantos pajarillos allí posados. Al pie figura esta leyenda: Arborem sublimam adque bustum, en que sería más correcta la palabra robustum, por lo que sin duda se trata de un error. Ignoramos lo que significa en este lugar la presencia de este «árbol sublime y robuston, que no se cita en el texto, salvo que fuera el Árbol de la Vida y por lo tanto una alusión más a la Salvación, iniciada con la Encarnación a la que se refiere la miniatura.

La semejanza de esta miniatura en el códice $\mathrm{G}$ y en el S es tan grande (salvo la ausencia del árbol en el segundo), que ambas tuvieron que ser muy fieles al modelo. Esta miniatura debería ser en T muy semejante a G, y en S muy parecida a $\mathrm{M}$, y a su vez en T casi idéntica a $\mathrm{M}$. La manera de dibujar el ala del pájaro, con dos semicírculos arriba y dos cenefas, que en $\mathrm{G}$ son ovadas, y lisas en S, y que separan los tres sectores de plumas del ala, son muy semejantes. El pecho está dividido por una línea que llega al cuello, con cenefa ovada en $\mathrm{G}$ y lisa en S, que separa la cabeza del cuerpo. El pico es recto en ambos códices, mientras que en $\mathrm{R}$ resulta ganchudo. En $\mathrm{S}$ y $\mathrm{G}$ la cola de la serpiente se pliega en anillos. G y S y la Biblia de la Real Academia de la Historia tienen la serpiente dividida en dos zonas paralelas de colores diferentes, lo que no ocurre en R. Ciertos detalles de la nube de polvo comparados en G, S y la citada Biblia llevan a la consecuencia de que S y la Biblia son los que están más cerca del modelo antiguo, ya que terminan en una especie de palmetas vegetales indicadoras de antigüedad, y por lo tanto S y la Biblia copiarían de manuscritos antiguos; en $\mathrm{G}$ se aprecia ya una primera transformación, y en $\mathrm{R}$ la última.

La colocación de esta escena en $\mathrm{G}$ es históricamente ilógica, porque está después de la Pasión y de la Resurrección, sin embargo, esta extraña situación de la Encarnación a posteriori, se explica porque en los Beatos más antiguos y en las Biblias, venía, como es natural, después de la Anunciación. Posteriormente y en los manuscritos de la familia $\mathrm{II}^{\mathrm{b}}$ y en $\mathrm{S}$ 
ésta se sustituyó por la Adoración de los Magos, y en lugar de rectificar la situación del águila y la serpiente, se dejó detrás de esta última escena, donde ya carecía de sentido. Como G y Tu aumentaron excepcionalmente el número de ilustraciones referentes a la vida de Cristo, la miniatura del ave quedó todavía más desplazada.

Esta miniatura está enfrentada en G con el folio que contiene el Alpha, que está en el 19 r., y el texto de la historia, de manera un tanto irregular, pasa detrás del Alpha (fol. 19 v.).

Lo mismo sería de esperar en Tu, ya que si perdió esta miniatura, conserva el texto cruciforme, pero está inmediatamente antes del comienzo de los Prólogos al Comentario al Apocalipsis; Neuss dice que no lleg6 a hacerse, pero que se reservó el sitio para ella, que correspondería al folio 15 v., en blanco, detrás de la Santa Cena; pero no tuvo en cuenta que se trata de un folio arreglado después del incendio de la Biblioteca de Turín, y pegado en un nuevo pergamino, por lo que su afirmación tiene escaso valor.

Otro detalle curioso: el códice $G$ ofrece en una viñeta, muy alejada de esta miniatura, ya que se encuentra en el folio $165 \mathrm{r}$., un dragón y frente a él un águila que eleva un ciervo con sus garras, lo que ya observó $\mathrm{M}$. Churruca, que publicó las dos miniaturas yuxtapuestas en fotomontaje ${ }^{21}$. No hay texto aclaratorio, pero esa otra águila con el ciervo entre las garras vuelve a evocar el texto de Plinio ya analizado.

\section{Beato $S$}

La miniatura de S es muy hermosa y ofrece semejanzas con la de G, que ya quedan analizadas y que conducen a curiosas hipótesis. También hay algunas diferencias, porque el pájaro tiene en $\mathrm{S}$ más movimiento al adelantar una de sus garras hacia la parte en posición vertical de la serpiente y clavarla en su cuerpo.

M. Churruca, en la página 60, dice: «Los miniados de G y S nos ofrecen ejemplares bellísimos para nuestro estudio. El segundo copia al primero.» Hay que objetar que S no copia de G, sino que ambos están emparentados a través de $\mathrm{M}^{22}$. Además de las diferencias de detalle anotadas no es fácil demostrar la relación de copia directa, lo que no impide una evidente semejanza no casual, aunque laxa, y sobre todo la gran calidad de la miniatura de S, una de las más bellas de los Beatos.

21 M. Churruca, op. cit., lámina XXV, v.

22 Aunque Neuss considera $S$ de la familia $I, 10$ mismo que Sanders, creemos que plásticamente está muy cercano a $\mathrm{M}, \mathrm{y}$ de ahú su parentesco con $\mathrm{G}$. 


\section{Beato $R$}

La miniatura de $\mathrm{R}$ se encuentra en el folio $14 \mathrm{r}$. Es un tanto particular porque águila, polvo y serpiente se entrelazan de manera estrecha, hierática y bien compuesta, posee elegante estilización y sentido cerrado de la composición. Frente a S, G y la Biblia de San Millán, la serpiente no tiene el cuerpo dividido en dos bandas de diferente color, sino por un sombreado

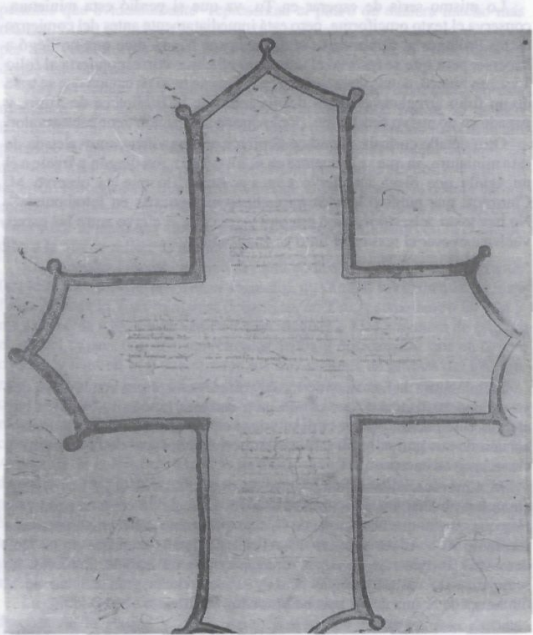

Foto 1. Texto de la leyenda del Águila y la Serpiente, con enmarque cruciforme: Beato firmado por Magius, Morgan Library, Nueva York. 
conseguido en parte por cambios cromáticos y en parte por rayitas paralelas y reiteradas de trazo caligráfico; además, su cuerpo no sólo se enrosca a la pata del águila formando un lazo, sino que hacia la mitad se complica con un nudo cerrado y apretado.

Tanto la ilustración de $\mathrm{G}$ como la de $\mathrm{S}$ son muy caligráficas y poco naturalistas, $y$ aunque $S$ es también románico, como $R$, está mucho más próximo al modelo mozárabe que copia de $\mathrm{R}$, donde la libertad es mayor y

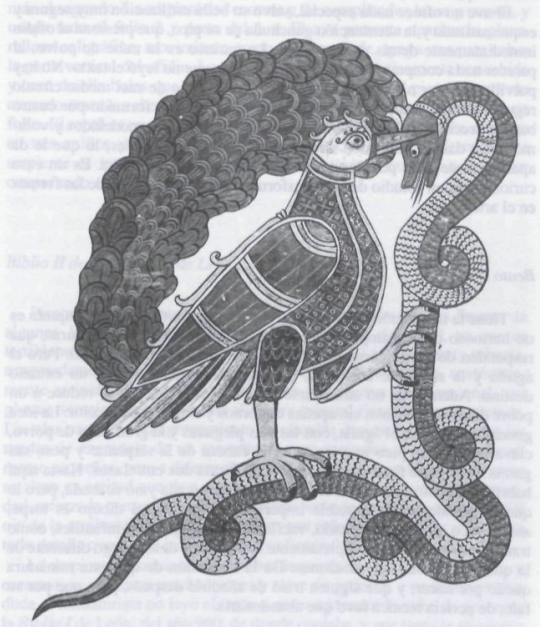

Foto 2. Un ejemplo de la miniatura del Águila y la Serpiente: Beato de Saint Sever, fol. 13 r., Bibliothèque Nationale, París. 
presenta un ave de rapiña de pico ganchudo bastante más naturalista, aunque la masa de polvo la dibujó de manera que demuestra su incomprensión por parte del miniaturista. La figura ya no es tan bidimensional como en $\mathrm{G}$ y $\mathrm{S}$ y tiende ya a una moderada expresión del volumen.

Si en $\mathrm{G}$ la serpiente parece sacar la lengua, en $\mathrm{S}$ muestra unas rayas que podrían ser estilización de fuego, semejante a la que se ve en la Biblia II de León, en el códice $\mathrm{R}$ arroja una grande e inconfundible llamarada de auténtico fuego que se bifurca varias veces, clara alusión al carácter infernal del reptil.

El ave no ofrece nada especial, salvo su bella estilización muy segura y esquematizada y la acentuación ganchuda de su pico, que presiona al ofidio inmediatamente detrás de la cabeza. Lo curioso es la nube de polvo, al parecer nada comprendida por el miniaturista, que no leyó el texto. No hay polvillo exterior ni masa de palmetas, sino un arco de casi medio círculo regular que va desde la cabeza hasta la cola del ave, formado por cuatro bandas seccionadas por unos elementos que, al pintarse modelados y volumétricos, dan la impresión de tejas o de tubos enchufados, lo que le da apariencia de gran pesadez y desde luego de falta de logica. Es un caso curioso para un estudio de las transformaciones psicológicas de las formas en el arte.

\section{Beato $U$}

Tiene la ilustración en el folio $\mathrm{V} v$. y es muy particular. En conjunto es un hermoso códice ampliamente ilustrado con brillantes miniaturas, que responden de modo normal a la época y estilo en que se ejecutó. Pero el águila y la serpiente corrieron, por razones desconocidas ${ }^{23}$, un extraño destino. Además de no adscribirse al texto, la ilustración se reduce a un pobre dibujo inacabado, sin apenas dintornos y sin relleno de color. La idea general es normal: el águila, con las alas plegadas y la gran nube de polvo, clava un enorme pico muy recto en la cabeza de la serpiente y posa sus garras en la parte final de su cuerpo, que forma dos entrelazos. Hasta aquí habría que conformarse con una miniatura empezada y no acabada, pero lo que sorprende es su increible imperfección, porque el dibujo es torpe, antiestético, desproporcionado, vacilante, con rasgos casi infantiles, como trazado por una mano completamente inexperta, y desde luego diferente de la que realizó otras ilustraciones. Da la impresión de que esta miniatura quedó por hacer, y que alguien trató de añadirle después, pero que por su falta de pericia técnica tuvo que abandonarla.

${ }^{23}$ Tal vez se deba a las distintas manos que intervinieron en el manuscrito. Algunos eruditos creen que esta parne biblica fue añadida tardíamente a causa de la encuadernación. 


\section{Biblia de San Millán}

Como sabemos, también algunas Biblias conservan la miniatura del águila y la serpiente. Una es la de San Millán o de la Real Academia de la Historia, que excepcionalmente le dedica dos folios, el 1 v. y el 2 r. Además de esta particularidad, presenta la anomalía de ser la única miniatura de este tema que conocemos enmarcada y con el fondo del pergamino relleno de ornamentos. Tiene la nube de polvo, y por la posición de las alas y la concepción del dibujo del águila se asemeja a G y S, quizás ligeramente más al segundo. La serpiente es enorme y de complicados lazos y curvas, y ocupa todo el folio 2 y parte del $1 \mathrm{v}$. El ave presenta apariencia plana, relleno caligráfico, movimiento como en $\mathrm{S}$, es decir, apoya una pata sobre la parte vertical del ofidio. La nube de polvo está artísticamente concebida y caen de ella bolas que envuelven a la serpiente; con el pico ligeramente curvado ataca la cabeza de su enemiga. Cada uno de los animales ocupa un folio. El reptil es muy curvilíneo, invade parte del folio del águila, se curva en tres anillos y está dividido en dos bandas de colores diferentes. La serpiente es intencionadamente mucho más larga y curvada para poder ocupar todo el folio.

\section{Biblia II de San Isidoro de León}

Presenta una miniatura algo torpe en comparación con las finuras de algunos Beatos, aunque impresiona por su fuerza elemental, ya que es terriblemente expresionista y carece de volumen. El águila es muy robusta, exageradamente hinchado su grueso cuerpo, la cola es enorme, anatómicamente antinatural, está vista de frente en perspectiva bidimensional, sus plumas semejan un tejido o una alfombra oriental ricamente omamentada. Las alas parten de un agrupamiento de círculos decorados que parecen las ruedas de engranaje de un mecanismo para moverlas, son proporcionalmente pequeñas, pero a diferencia de todas las demás, en lugar de plegarse se alzan en actitud que da a esta imagen una fuerte impresión de agresividad, reforzada porque el águila ha hundido parte de su pico en el interior del ojo de la serpiente, Las garras del pájaro son colosales y en ellas se exagera todo detalle que pueda indicar fuerza y eficacia hiriente.

La serpiente, gruesa, con doble banda paralela de diferentes colores y escamas, se entrelaza muchas veces y sirve de pedestal a su enemigo. Sin duda el miniaturista no leyó el texto y no comprendió la nube de polvo de la Biblia I de León, del año 960, de donde copiaba, y por tanto la eliminó y trató de que la lucha fuera lo más realista posible. Para ello recurrió al traumatismo de cegar a la serpiente; pero respecto a la decoración siguió 
fielmente el modelo. Los animales, a pesar de todo, son en sí mismos muy ornamentales, y su falta de volumen los aleja del posible naturalismo.

Tal es el aspecto que presenta esta Biblia, en tres volúmenes escritos con letra carolingia, hacia el año 1162, siendo abad de San Isidoro cierto Menendo, y de la cual sabemos que un canónigo fue a buscar a Francia el pergamino, que se tardó seis meses en ilustrarla y que se ilumin 6 al séptimo. Lástima que se perdiera la ilustración de su original mozárabe. aunque la que conocemos puede dar buena idea de ella debido a su evidente arcaismo en fecha tan avanzada.

\section{Las $\propto$ Moralia $\gg$ de San Gregorio}

Además de en los Beatos y en las Biblias, el águila y la serpiente también aparece en otro tipo de manuscrito, en las Moralia de San Gregorio, en el folio 172 v. del códice de la catedral de Burgo de Osma. Ocupa únicamente la parte superior izquierda del folio, ya que va acompañada del texto. Desapareció la nube de polvo, las alas están tratadas de manera muy diferente a G y S, el animal carece de elegancia, y quizás un intento de presentación de las alas en perspectiva tridimensional fracasó, de modo que toda el ave resulta un extraño y confuso revoltijo de plumas. Como en $\mathrm{S}$, monta sobre la serpiente y, como en la Biblia II de León, introduce el pico en el interior del ojo de la serpiente, que es un sencillo reptil tres veces enroscado y dividido en dos bandas paralelas de diversos colores. En conjunto la miniatura carece de la elegancia y señorial dominio de su especie.

\section{Beato $H$}

El comentario de otro Beato al final de esta exposición, después de analizar cuantos poseen la miniatura, y después de tratar de las Biblias y las Moralia, parece un auténtico desorden. Sin embargo, responde a una razón lógica. Todo cuanto hasta aquí se ha expuesto se refiere a una miniatura en que gráficamente se representa la lucha de un águila con una serpiente, se trate de una u otra clase de códices respecto al texto. El Beato $H$ es un caso excepcional y muy curioso. Si literalmente esperamos ver al pajaro y al reptil, no los hallamos y podría creerse que carece de ellos, como otros. Sin embargo, existe el texto cruciforme enmarcado con filete caligráfico de esta misma forma, sólo que está relacionado con otra miniatura de aspecto totalmente diferente a las ya estudiadas, sin que tal cambio se explique por pérdida o mala encuadernación, porque esta circunstancia no se produce. El motivo es que se mantiene el espíritu, pero se cambia la visualidad. 
Sucede que la miniatura del águila y la serpiente se funde con la del ángel apocalíptico con la que comienza el texto del Comentario de Beatus en la segunda rama de la familia IIb. Como afirma Weissbach ${ }^{24}$, el ángel que aparece en este caso es el arcángel San Miguel, dominador de Satán, que dirige su lanza contra el dragón tendido a sus pies, mientras que en los demás manuscritos, por ejemplo, $\mathbf{R}$, es simplemente un ángel con libro en la mano y sin arma ni monstruo.

El cambio, que parece absurdo, es perfectamente explicable dentro de la mentalidad románica avanzada del manuscrito $\mathrm{H}$; en lugar de un pájaro hay un ángel (en último término dos seres alados, sólo que en el segundo caso humanizado) con una cruz de largo astil terminado por abajo en punta de lanza, con la que atraviesa la cabeza de una serpiente alada que tiene bajo sus pies, evidente contaminación de la iconografía típica del arcángel San Miguel. Por razones de composición y relleno, por horror vacui, hay a los lados dos aves de larguísimos cuellos y colas serpentiformes. El acostumbrado texto aparece encarado con esta figuración en el folio siguiente.

Hasta ahora queda clara la presencia de Satán y de su vencimiento por un ser alado. En las equivalencias simbólicas la punta de la lanza es el pico del ave, las alas aluden a las del pájaro, su cuerpo humano a la humanidad que en una mentalidad prelógica fuertemente simbólica como la mozárabe contenía oculta el pájaro, la de Cristo. Pero desde un punto de vista mucho más racionalizado, como el románico, la miniatura se completa arriba con una auténtica figura de Cristo bendiciendo (señala el dedo segundo de su mano, vieja fórmula que le define precisamente como la Segunda Persona de la Trinidad), con libro y enmarcado en mandorla sostenida por dos ángeles tenantes. De este modo no queda la menor duda de que el auténtico vencedor es Cristo en su divinidad humanizada de modo visible e inequívoco.

Se trata de un ejemplo muy curioso de racionalización románica de un tema heredado del mozárabe, que cambia las apariencias para hacerlas más comprensibles sin alterar el contenido. Es un fenómeno muy típico que ya analizamos en general en una comunicación al Congreso Internacional del CSIC celebrado en Madrid en octubre de 1964, con el título de La crisis del Arte español en torno al año mil, a través de las miniaturas mozárabes y románicas. Desde el punto de vista de la psicología del arte, puede calificarse de transferencia de simbolismo de una imagen y su sincretismo con otra para racionalizar e intensificar la comunicación cuando un código, al anticuarse, se ha convertido en débil, y su sustitución por otro que es fuerte dentro de la nueva situación mental impuesta por la evolución cultural. De paso, significó la muerte

24 WeISSEACH, Reforma religiosa y Arte medieval, p. 71. 
de la vieja miniatura de la lucha del águila y la serpiente, y al justificar el desglose del Beato $\mathrm{H}$ para el final de este trabajo, lo cierra de modo natural, como clausuró una ilustración secular que, como todo en la vida, cumplió su misión y perdió su razón de ser cuando le llegó su momento, y al ceder ante nuevas estructuras mentales, se disolví́ en ellas y desapareció para siempre. 